\title{
CONTRIBUTION OF HYPEROXIA TO LIPID PEROXIDATION IN CORONARY ARTERY OPERATIONS: SHOULD WE KEEP A LOW OXYGEN TENSION?
}

\author{
Leonidas Hadjinikolaou, MD, Andrew Cohen, FRCS, Hany Hafez, FRCS, William Richmond, PhD,
} and Brian Glenville, MS, FRCS, London, United Kingdom

Oxygen free radicals are known to play a significant role in the morbidity associated with cardiac operations. They seem to be produced through two major pathways, heart ischemia-reperfusion ${ }^{1}$ and leukocyte activation. ${ }^{2}$ Another possible pathway might be the hyperoxia that occurs during cardiopulmonary bypass (CPB) and within a short period during which the patient is still supported by mechanical ventilation. The contribution of hyperoxia to oxygen free radical generation and consequent lipid peroxidation in cardiac operations has to date not been addressed. The purpose of the present study was to elucidate the role of hyperoxia in lipid peroxidation during cardiac operations.

Patients and methods. After obtaining informed consent, we entered 24 consecutive patients scheduled for routine coronary artery operation into the study. Patients in cardiogenic shock were excluded from the study. The mean age was $63.2 \pm 2.1$ years (range 44 to 83 ) and there were 17 men and 7 women. Ischemic time was $46.8 \pm 3.2$ minutes (range 24 to 92 ) CPB time $98.7 \pm 5.4$ minutes (range 67 to 174), and blood partial $\mathrm{O}_{2}$ tension $\left(\mathrm{PO}_{2}\right)$ during CPB $45.4 \pm 1.2 \mathrm{kPa}$ (range 29 to 57 ). Anesthesia was instituted with fentanyl, pancuronium, and isoflurane. A membrane oxygenator (CML membrane hollow-fiber oxygenator, Cobe Inc., Lakewood, Colo.) was used for extracorporeal circulation and $\mathrm{pH}$ management was done with the pH-stat method. Myocardial protection was achieved with the use of intermittent fibrillation. The nasopharyngeal temperature was maintained at approximately $32^{\circ} \mathrm{C}$ during the $\mathrm{CPB}$ period. No patient received drugs known specifically to scavenge free radicals (allopurinol, mannitol, captopril, and desferrioxamine). Anesthetists and perfusionists responsible for controlling the degree of oxygenation were blind to the study.

Peripheral venous blood samples for determination of whole plasma hydroperoxide concentrations (WPHC) were obtained before the operation and $1,6,24$, and 72 hours after CPB was discontinued. The venous blood

From the Department of Cardiothoracic Surgery and Metabolic Medicine, St. Mary's Hospital, Medical School, Imperial College of Science, Technology and Medicine, London, United Kingdom.

Received for publication May 28, 1996; accepted for publication July 17, 1996.

Address for reprints: Leonidas Hadjinikolaou, MD, Cardiothoracic Surgery, St. Mary's Hospital, Praed St., London W2 1NY, United Kingdom.

J Thorac Cardiovasc Surg 1997;113:212-3

Copyright (C) 1997 by Mosby-Year Book, Inc.

$0022-5223 / 97 \$ 5.00+0 \quad \mathbf{1 2 / 5 4 / 7 6 8 3 1}$ samples were drawn into vacuum tubes containing dry lithium-heparin, placed immediately on ice, and the plasma separated on a centrifuge $\left(4^{\circ} \mathrm{C}, 3000 \mathrm{rpm}, 10\right.$ minutes) within 30 minutes. The separated plasma was then immediately frozen to $-75^{\circ} \mathrm{C}$ until assayed. WPHC were measured with use of the Peroxoquant kit (lipid compatible formulation) purchased from Pierce \& Warriner Ltd., Chester, United Kingdom. Arterial blood samples for determination of blood gas values were obtained from the radial artery at the corresponding times (288 blood gas system, Ciba-Corning, Inc., Medfield, Mass.).

Data were analyzed with the Statgraphics statistical program (Statgraphics, version 6.0, Manugistics, Inc., Rockville, Md.). Two-way analysis of variance was used to describe changes over time. Linear, nonlinear, and multiple regression analyses were used to identify relationships between WPHC, $\mathrm{PO}_{2}$, and other related variables. Results were expressed as mean plus or minus standard error and differences were considered significant at a probability level of $p$ less than 0.05 .

Results. No patient received inotropic support during or after the operation and none of them had any significant complication during the 72 hours of observation. Time changes of WPHC and $\mathrm{PO}_{2}$ values are presented in Fig. 1. The WPHC 1 hour after CPB was related to neither $\mathrm{PO}_{2}$ at the corresponding time nor mean $\mathrm{Po}_{2}$ during $\mathrm{CPB}$ $(p=0.44, r=-0.16$ and $p=0.37, r=-0.19$, respectively). Multiple regression analysis showed that $\mathrm{Po}_{2}$ levels during CPB did not influence the WPHC 1 hour after $\mathrm{CPB}$, even when $\mathrm{CPB}$ time was taken into account (Table I).

Discussion. Lipid peroxidation, although absent during CPB, has been shown to be present in the first few hours after its discontinuation. ${ }^{3}$ Hyperoxia, which is known to increase the formation rate of oxygen free radicals (superoxide, hydrogen peroxide, and hydroxyl radical) and lipid peroxides, ${ }^{4}$ is present during and for several hours after CPB. In this study significant hyperoxia, almost four times the baseline value, occurred during

Table I. Multiple regression analysis for WPHC 1 hour after $C P B$

\begin{tabular}{lrrr}
\hline & Coefficient & $S E$ & $p$ Value \\
\hline Dependent variable & & & \\
WPHC 1 hour after CPB & & & \\
Independent variables & & & \\
$\quad$ mean $\mathrm{PO}_{2}$ during CPB & -0.14 & 0.18 & 0.43 \\
CPB time & 0.04 & 0.04 & 0.34 \\
\hline$p$ Value for the full regression $=0.43 . S E$, Standard error.
\end{tabular}




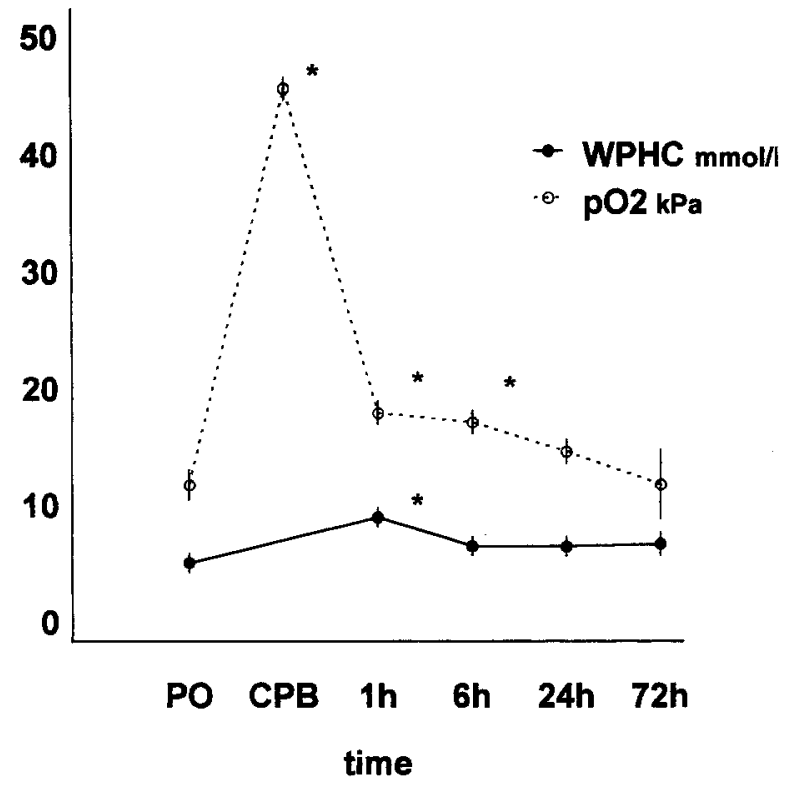

Fig. 1. Time changes of $\mathrm{WPHC}$ and $\mathrm{PO}_{2}$ values in coronary artery operations undertaken with $\mathrm{CPB}$. Results are expressed as mean and standard error. $P O$, Preoperative; *, statistically significant difference from baseline value.

$\mathrm{CPB}$ and persisted at lower levels for at least 24 hours after the operation. Plasma hydroperoxide concentration, an index of lipid peroxidation with high precision, ${ }^{5}$ was found to increase only 1 hour after CPB and had returned to the normal range after 6 hours. Furthermore, the degree of hyperoxia during and after CPB was not found to be related to the levels of lipid peroxidation. This lack of relationship persisted even when the CPB time, an index of the duration of exposure to hyperoxia, was taken into account.

In conclusion, early post-CPB lipid peroxidation cannot be explained by the degree or the duration of hyperoxia alone, and therefore ischemia-reperfusion, leukocyte activation, and antioxidant defense system impairment may remain the major pathogenic mechanisms. Thus attempts to reduce the high $\mathrm{PO}_{2}$ levels during cardiac operations, to protect from oxygen free radical damage, may not be vital. More aggressive measures with antioxidant supplementation may be more important.

\section{REFERENCES}

1. Hammond B. Hess ML. The oxygen free radical system: potential mediator of myocardial injury. J Am Coll Cardiol 1985;6:215-20.

2. Cavarocchi NC, England MD, Schaff HV, et al. Oxygen free radical generation during cardiopulmonary bypass: correlation with complement activation. Circulation 1986;74(5pt2): III130-3.

3. Davies SW, Duffy JP, Wickens DG, et al. Time-course of free radical activity during coronary artery operations with cardiopulmonary bypass. J Thorac Cardiovasc Surg 1993;105:979-87.

4. Jamieson D, Chance B, Cadenas E, Boveris A. The relation of free radical production to hyperoxia. Ann Rev Physiol 1986; 48:703-19.

5. Nourooz-Zadeh J, Tajaddini-Sarmadi J, Wolff SP. Measurement of plasma hydroperoxide concentrations by the ferrous oxidation-xylenol orange assay in conjunction with triphenylphosphine. Anal Biochem 1994;220:403-9. 